\title{
Prevalence of myofascial trigger points in post-stroke patients with painful shoulders: a cross sectional study
}

\section{CORRESPONDING AUTHOR CONTACT INFORMATION}

\begin{tabular}{|c|c|}
\hline $\begin{array}{l}\text { For the corresponding author (responsible for } \\
\text { correspondence, proofreading, and reprints) }\end{array}$ & Fill in information in each box below \\
\hline First name, middle initial, last name and degrees & Jorge Hugo Villafañe, $\mathrm{PhD}$ \\
\hline Email address & mail@villafane.it \\
\hline Postal mailing address & Piazzale Morandi 6, Milan (20121), Italy \\
\hline \multicolumn{2}{|l|}{ Phone number } \\
\hline Fax number & +39.011 .9065495 \\
\hline \multicolumn{2}{|l|}{ First author } \\
\hline $\begin{array}{l}\text { First name, middle initial, last name of author. } \\
\text { Include highest academic degree(s) }\end{array}$ & Jorge Hugo Villafañe, PhD, MSc \\
\hline Email address & mail@villafane.it \\
\hline \multicolumn{2}{|l|}{ Title, academic or professional position } \\
\hline $\begin{array}{l}\text { Name of department(s) and institution(s) to which } \\
\text { work should be attributed for this author. }\end{array}$ & $\begin{array}{l}\text { IRCCS Fondazione Don Carlo Gnocchi, } \\
\text { Milan, Italy }\end{array}$ \\
\hline \multicolumn{2}{|l|}{ Second author } \\
\hline $\begin{array}{l}\text { First name, middle initial, last name of author. } \\
\text { Include highest academic degree(s) }\end{array}$ & Maria Pilar Lopez-Royo, MSc, PT \\
\hline Email address & mapilr86@hotmail.com \\
\hline Title, academic or professional position & PhD, Studentship \\
\hline $\begin{array}{l}\text { Name of department(s) and institution(s) to which } \\
\text { work should be attributed for this author }\end{array}$ & University of Zaragoza, Spain \\
\hline \multicolumn{2}{|l|}{ Third author } \\
\hline $\begin{array}{l}\text { First name, middle initial, last name of author. } \\
\text { Include highest academic degree(s) }\end{array}$ & Pablo Herrero, PhD, MSc, PT \\
\hline Email address & pherrero@usj.es \\
\hline Title, academic or professional position & Professor \\
\hline $\begin{array}{l}\text { Name of department(s) and institution(s) to which } \\
\text { work should be attributed for this author }\end{array}$ & $\begin{array}{l}\text { iPhysio Research Group, Universidad San } \\
\text { Jorge, Villanueva de Gállego Zaragoza, } \\
\text { Spain }\end{array}$ \\
\hline
\end{tabular}

\section{Fourth author}

First name, middle initial, last name of author.

Include highest academic degree(s)

Email address

Title, academic or professional position

Name of department(s) and institution(s) to which

work should be attributed for this author

Fifth author

First name, middle initial, last name of author.

Include highest academic degree(s)

Email address

Title, academic or professional position

Name of department(s) and institution(s) to which

work should be attributed for this author

Kristin Valdes, OTD, OT, CHT

Valdes001@gannon.edu

Assistant Professor

Gannon University, Ruskin, FL, USA

\section{Sixth author}

First name, middle initial, last name of author.

Paolo Pedersini, PT

This article has been accepted for publication and undergone full peer review but has not been through the copyediting, typesetting, pagination and proofreading process, which may lead to differences between this version and the Version of Record. Please cite this article as doi: 10.1002/pmrj.12123 


\begin{tabular}{|l|l|}
\hline Include highest academic degree(s) & \\
\hline Email address & pedersini93@gmail.com \\
\hline Title, academic or professional position & Physical therapist \\
\hline $\begin{array}{l}\text { Name of department(s) and institution(s) to which } \\
\text { work should be attributed for this author }\end{array}$ & $\begin{array}{l}\text { IRCCS Fondazione Don Carlo Gnocchi, } \\
\text { Milan, Italy }\end{array}$ \\
\hline
\end{tabular}

\section{Seventh author}

\begin{tabular}{|l|l|}
\hline $\begin{array}{l}\text { First name, middle initial, last name of author. } \\
\text { Include highest academic degree(s) }\end{array}$ & Stefano Negrini, MD \\
\hline Email address & stefano.negrini@med.unibs.it \\
\hline Title, academic or professional position & Professor \\
\hline Name of department(s) and institution(s) to which & $\begin{array}{l}\text { 1.Department of Clinical and Experimental } \\
\text { work should be attributed for this author }\end{array}$ \\
& Sciences, University of Brescia. \\
& 2.IRCCS Fondazione Don Carlo Gnocchi, \\
& Milan, Italy. \\
\hline
\end{tabular}

\section{ACKNOWLGEMENTS}

The authors thank Gianluigi Sacella, PT, for your assistance.

Declaration of interest: The authors report no conflicts of interest. The authors alone are responsible for the content and writing of the paper.

\section{ABSTRACT}

Background: In patients with stroke, hemiplegic shoulder pain can be a major problem. One source of shoulder pain can be Myofascial Trigger Points (MTrPs).

Objective: To determine the prevalence of Myofascial Trigger Points (MTrPs) and the correlation between MTrPs and pain and function in patients presenting with shoulder pain following a stroke.

Design: Cross sectional study

Setting: IRCSS Fondazione Don Carlo Gnocchi.

Patients: A total of 50 patients with stroke with shoulder pain.

Intervention: Not applicable

Main outcome measurments: The prevalence of the MTrPs located in infraspinatus, supraspinatus, teres minor, and upper trapezius was studied, using the diagnosis criteria 
recommended by Simons, Travell, and Simons. The pressure pain threshold was also evaluated. Pain and functionality were assessed with Visual Analogue Scale (VAS) and The Disability of the Arm, Shoulder and Hand scale (DASH), respectively.

Results: The prevalence of latent MTrPs was estimated to have a rate of $68 \%, 92 \%, 40 \%$ and $62 \%$ for supraspinatus, infraspinatus, teres minor, and upper trapezius muscle, respectively. The prevalence of active MTrPs was estimated to have a rate of $34 \%, 50 \%$, $12 \%$ and $20 \%$ for supraspinatus, infraspinatus, teres minor, and upper trapezius muscle respectively. Pain was measured with the VAS scale and was moderately correlated with the prevalence of latent MTrPs $(r=.35 ; p=.01)$ and active MTrPs $(r=.31 ; p=.03)$ in the supraspinatus muscle. Disability was measured with the DASH and was moderately correlated with latent MTrPs in infraspinatus ( $r=.31 ; p=.03)$ and active MTrPs of supraspinatus $(r=.32 ; p=.02)$.

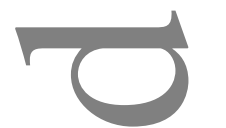

Conclusions: This study shows that prevalence of MTrPs is high in patents following a stroke. Further longitudinal studies are needed to determine the presence of MTrPs in this specific population.

Level of evidence: II

Trial registration: ClinicalTrials.gov Registration Number: NCT02882906.

Key words: myofascial pain, shoulder, stroke. 


\section{INTRODUCTION}

In neurological patients, hemiplegic shoulder pain (HSP) can be a major problem ${ }^{1}$. The incidence of hemiplegic shoulder pain varies from $16 \%$ to $84 \%{ }^{2}$. Prior studies have documented the negative impact of HSP including: obstruction of the rehabilitation process, delay of motor recovery in the upper extremities, decrease in the functional performance of daily activities, and prolongation of hospital stay, and has been associated with depression and decreased quality of life ${ }^{3}$. One third of all individuals seeking physician

Jintervention for musculoskeletal pain in the United States are seeking relief for shoulder pain ${ }^{4}$. The causes of the pain can be difficult for clinicians to diagnose due to the complexity of the shoulder anatomy and the wide spectrum of shoulder conditions ${ }^{5}$. Soft tissue injury or degenerative changes of the bone structures may cause painful shoulder conditions $^{6,7}$.

One source of shoulder pain can be Myofascial Trigger Points (MTrPs). MTrPs are localized, hyperirritable points that are associated with palpable nodules in taut bands (TB) of muscle fibres ${ }^{8}$. MTrPs can be classified into active and latent ${ }^{9}$. Latent MTrPs demonstrate the same clinical characteristics as active MTrPs but they do not provoke spontaneous pain ${ }^{10}$. Numerous studies have shown that MTrPs are prevalent in patients ( with chronic non-traumatic neck and shoulder pain ${ }^{11,12,13}$. A study of 72 patients with Shoulder pain showed a high prevalence of active MTrPs in the infraspinatus (78\%) and upper trapezius muscles $(58 \%)^{11}$. Persistence of MTrPs in the neck and shoulder muscles for long periods may result in headache, neck and shoulder pain, dizziness or vertigo, limited neck and shoulder range of motion, abnormal sensation, and dysfunction, and disability ${ }^{14,15}$. To the best of our knowledge there are no studies regarding the prevalence of MTrPs in patients after stroke with shoulder pain. Such findings could open up new therapeutic perspectives in this group of patients as Tang L. et al have done when they 
studied the intervention of dry needling to resolve MTrPs in patients post-stroke with shoulder pain ${ }^{16}$.

Our hypothesis was that the prevalence of MTrPs may be high in patients with stroke and therefore may be considered as a source of pain and dysfunction. The aim of this study was to determine the prevalence of MTrPs and the correlation between MTrPs and pain and function in patients presenting with shoulder pain following a stroke.

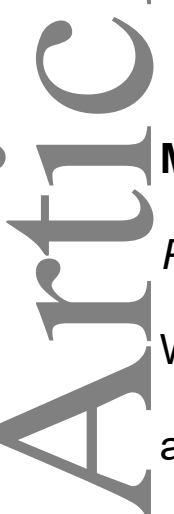

\section{MATERIAL AND METHODS}

\section{Participants}

We conducted a cross sectional study in male and female stroke subjects between the ages of 30 to 85 with the diagnosis of unilateral shoulder pain. Informed consent was obtained from all participants and the procedures were conducted according to the Declaration of Helsinki. This research protocol has been approved by the Local Ethical Committee of "IRCCS Fondazione Don Carlo Gnocchi", Italy on 24 February 2016 and is registered with ClinicalTrials.gov (NCT02701335). Before the experimental procedure, the evaluation protocol was explained to each subject, making sure that the patient understood the whole process.

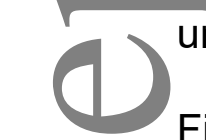

Fifty-five consecutive inpatients with a complaint of shoulder pain following a stroke were recruited from the department of physical therapy of the "Spalenza-Don Gnocchi" center. Testing took place between the hours of 9:00 am and 12:00 am. The subjects were screened and enrolled the study during the calendar year 2016. All subjects presented with unilateral HSP.

\section{Inclusion and exclusion criteria}

Data collection method was planned prior to the physical and palpation tests. A physiatrist reviewed the MRI results and screened the patient's medical history to determine if the patient was eligible for inclusion. Inpatients were included in the study if they were, (30-85 
years old) during the first 3 months after stroke, with shoulder pain and a degree of spasticity of Ashworth scale $>2$ and without flaccidity. Subjects could either be ambulatory with or without an assistive device or non-ambulatory, Subjects, having any of the following disorders were excluded: rheumatic inflammatory, diabetes mellitus, fibromyalgia, metabolic syndrome, acute traumatic conditions, postoperative conditions, cervical spine disorders, shoulder and elbow disorders, and receptive or expressive aphasia as determined by the Quick Aphasia Battery (QAB). Demographic information gathered included: the patients' age, sex, type of stroke, hemiplegic side, characteristics of pain, and any additional problems, medicines and infiltrations ${ }^{17}$. A detailed physical examination was performed on all patients. All patients were clinically stable and they all underwent subjective and objective physical examination performed by two physical therapists with experience in management of shoulder conditions. The STROBE statement checklist of items of cohort observational studies were fulfilled in this study ${ }^{18}$.

\section{Outcome Measures}

Before the start of the evaluation, the clinicians underwent training to standardize the examination techniques and the interpretation of the tests. Each of the two clinicians independently performed a standardized history and physical examination of each patient.

\section{PRIMARY OUTCOME MEASURE}

\section{Palpation Intervention}

The presence of MTrPs in infraspinatus, supraspinatus, teres minor, and upper trapezius was recorded as the primary outcome variable. The therapist explores the muscle doing perpendicular palpation to the direction of the fibers to feel taut bands in order to select MTrPs on the muscle. The therapist moves longitudinally to the selected taut band to feel if there is some painful spot or nodule into the taut band, and if the painful spot corresponds with the nodule. After a MTrP has been diagnosed, a compression test is carried out to classify them between active or latent MTrPs. Examiner applied compression for 30 
seconds, and asked the participants if they experienced any referred pain. Patients were asked if the compression test reproduced referred pain that was familiar for them, in which case the MTrPs were considered active.

To perform the palpation of the MTrPs in the infraspinatus, the patient took their shirt off. We disinfected and cleaned the shoulder zone and the hands of the examiner. The clinician placed the patient in a seated position with their arms relaxed along the sides of the body and then stood behind the patient. To perform the palpation of supraspinatus and teres minor for MTrPs with the patient's arm relaxed, with the shoulder externally rotated $30^{\circ}$ and the elbow positioned in $90^{\circ}$ of flexion. Finally, to palpate for upper trapezius MTrPs, the patient was supine with their arms relaxed to the side of the body.

The criteria recommended by Simons, Travell, and Simons ${ }^{10}{ }^{19}$ were used to diagnose MTrPs considering 4 criteria:

\footnotetext{
P - Is there a taut band (TB)?

- Is there a palpable nodule in the taut band (NE)?

- Is there a hypersensitive point (HP)?

- Is there referred pain familiar to patient's pain (RP)?
}

After each palpation, the clinician answered the following questions with a YES or NO (Table 1). If all the answers were YES, the clinician determined that they had palpated an active $M T r P$, since it fulfilled all the characteristics described in the literature to locate a MTrP. A 'latent' MTrP was determined when all answers were YES except for the last one (it did not produce a recognizable pain) ${ }^{20}$.

\section{SECUNDARY OUTCOME MEASURE}

\section{Test and Scales}

Before the palpation test, the clinician administered two questionnaires, the Barthel Index and The Disabilities of the Arm, Shoulder and Hand Score (DASH) to evaluate the disability of the subject and the specific function of the upper limb, respectively 102122 . 
Pain - Visual Analogue Scale (VAS)

Patients were asked about their current pain with a VAS, where 0 was absence of pain and 100 was intense pain. Immediately after this, the clinician examined the shoulder muscles for the presence of MTrPs.

\section{Statistics}

Data were analyzed using SPSS for Windows (V.22, IBM, Armonk, NY, USA). Descriptive statistics (mean and standard deviation) were provided for all subjects, as well as for males and females, respectively. The relationships between the 4 MTrPs (infraspinatus, supraspinatus, teres minor, and upper trapezius) and pain and function were assessed using Pearson's correlation coefficients. Statistically significant correlation coefficients of $<.30$ were considered to be indicative of a poor correlation. A correlation coefficient of $\geq .30$ and $\leq .70$ was considered to be indicative of moderate correlation, and a correlation coefficient of $\geq .70$ was defined as a strong correlation.

- Sample size calculations were performed based on a priori power calculation with a mean difference of $2 \mathrm{~cm}(\mathrm{MDC})$ on a $10 \mathrm{~cm}$ VAS assuming a standard deviation of $2 \mathrm{~cm}$, a 2-tailed test, an alpha level of .05 , and a desired power of $80 \%$. A statistical power analysis indicated that a minimal sample size of 50 subjects was needed. The sample size was performed with the ENE 3.0 software (GlaxoSmithKline@), Universidad Autónoma, Barcelona).

\section{RESULTS}

Clinical characteristics of the participants

A total of 33 men and 17 women, aged 30 to 85 years (mean, 68.5; SD, 10.7 years), with post-stroke shoulder pain participated in this study. Descriptive statistics for demographics, pain, and functional assessments including mean values of the DASH, Barthel, and VAS scores are presented in Table 2. Regarding the reference values at baseline, the following 
mean scores were found: $52.2 \pm 27.7$ for Barthel's index, $73.9 \pm 18.7$ for DASH questionnaire, and $50.3 \pm 22.9$ for shoulder pain measured with the VAS.

\section{Prevalence of MTrPs by muscle}

We combined the performance of clinical tests to determine if it was possible to improve the diagnostic value of the presence of latent and active MTrPs. To confirm a latent MTrP, a positive answer to all of the three first questions (TB, NE, and HN) was necessary, whilst to confirm an active MTrP it was necessary also to reply YES to the fourth question (RP). MTrPs were found in the infraspinatus $(n=46)$, supraspinatus $(n=34)$, upper trapezius $(n=31)$, and teres minor $(n=20)$ muscles. After classifying them into active or latent according the aforementioned criteria, it was found that the presence of active MTrPs in each muscle were as follows: infraspinatus $(n=25)$, supraspinatus $(n=17)$, upper trapezius $(n=10)$, and teres minor $(n=6)$. The presence of latent MTrPS were as follows: infraspinatus $(n=21)$, supraspinatus $(n=17)$, upper trapezius $(n=21)$, and teres minor ( $(n=14)$ muscles. Figure 1 presents the distribution of active and latent MTrPs per muscle.

Prevalence of Latent and active MTrPs

The prevalence of latent MTrPs in this population was estimated to have a rate of $68 \%$, $92 \%, 40 \%$ and $62 \%$ for supraspinatus, infraspinatus, teres minor and upper trapezius muscles respectively. The prevalence of active MTrPs was estimated to have rate of $34 \%$, $50 \%, 12 \%$ and $20 \%$ for the supraspinatus, infraspinatus, teres minor and upper trapezius muscles respectively (Table 3 ).

Correlation between MTrPs and pain and disability scores

Pain was measured with the VAS scale and was moderately correlated with the prevalence of latent MTrPs $(r=.35 ; p=.01)$ and active $\operatorname{MTrPs}(r=.31 ; p=.03)$ in the supraspinatus muscle. Disability was measured with the DASH and was moderately 
correlated with latent MTrPs in infraspinatus $(r=.31 ; p=.03)$ and active MTrPs of supraspinatus $(r=.32 ; p=.02)$ (Table 4.).

\section{DISCUSSION}

Shoulder pain following stroke can be caused from impaired motor function (muscle tone changes), rotator cuff and biceps tendon disorders, adhesive capsulitis, and altered peripheral or central nervous system (CNS) activity (complex regional pain syndrome type 1, peripheral nerve entrapment, neglect, sensory impairment, central pain, central sensitization), or Myofascial Trigger Points ${ }^{23},{ }^{24}$. To determine the etiology of pain can require a battery of tests including: Magnetic Resonance Imaging (MRI), manual muscle testing, passive range of motion, and palpation.

This study confirmed our hypothesis, that in a specific population of patients following a stroke, MTrPs are prevalent and therefore they should also be specifically examined and treated as in a non-stroke population, as they can also be a source of shoulder pain and dysfunction. Regarding active MTrPs in supraspinatus, they were moderately correlated with both the VAS and DASH, thus the evaluation of the presence of MTrPs is key when assessing a patient with HSP. Latent MTrPs in infraspinatus were moderately correlated with the DASH score but not with the VAS score. This may show the importance of the role of MTrPs as a potential source of disability.

To date, there are no published studies of the prevalence of MTrPs in this population. Bron et al. studied the prevalence of MTrPs in subjects with shoulder pain without neurological condtions $^{11}$. Compared with Bron et al., we found very similar prevalences rates for the infraspinatus ( $92 \%$ in this study and $93 \%$ found by Bron et al.) and supraspinatus (68\% in this study vs $60 \%$ found by Bron et al. ${ }^{11}$ ). When we compared the prevalence of only active MTrPs with results found by Bron et al. we just found the same prevalence in supraspinatus (34\% vs $35 \%$ ), whilst in the infraspinatus the prevalence of active MtrPs 
was considerably lower despite the finding that the overall prevalence of MTrPs was similar $^{11}$. This may be explained by two hypotheses. The first one is that although the prevalence of MTrPs is similar, they are not primarily responsible of pain in this population of patients. The second one is that the criteria to classify the MTrPs into active MTrPs (positive criteria of referred pain familiar to the patient) are not reliable for a population with sensory alterations, like those that occur following a stroke. In fact, although active MTrPs were not correlated with pain despite its high prevalence, latent MTrPs in the infraspinatus showed a moderate correlation with DASH. Perhaps the (RP) criteria used to classify MTrPs is the most useful. According to our clinical experience treating these patients and obtaining good results after specific MTrP therapy, we think that the criteria "referred pain familiar to the patient" has a potential high risk to yield false negatives in this population, so in neurologically impaired patients the specific examination should consider this criteria with caution.

The incidence of TrPs is very common in general population, and the prevalence in around $30 \%$ of pain patients consulting in primary care ${ }^{25}$. Hidalgo-Lozano et al. assessed the prevalence of MTrPs in 12 patients with unilateral shoulder impingement syndrome compared to healthy controls and found the point prevalence of active MTrPs was most predominant in supraspinatus $(67 \%)$, infraspinatus $(42 \%)$ and subscapularis $(42 \%)^{26}$. In contrast, we found the highest prevelence of active MTrPs in the infraspinatus $(50 \%)$, followed by the supraspinatus (34\%), Fernández-De-Las-Peñas et al. analysed the prevalence of active MTrPs in the head, neck and arm between manual and office workers with nonspecific neck or shoulder pain ${ }^{27}$. They found a similar number of MTrPs in the upper quadrant musculature with the most prevalent being upper trapezius, infraspinatus, levator scapulae, and extensor carpi radialis brevis muscles for both groups $^{27}$. We are in agreement with their study as we also found the highest prevelence for both latert and active MTrPs.to occure in the infraspinauts muscle. However, we found 
a higher prevelence of latent MTrPs and they reported there was not a significant difference between active and latent MTrPs in their study ${ }^{27}$.A recent systematic review reported that latent MTrPs did not consistently have a higher prevalence compared to healthy controls ${ }^{28}$

For future studies, it would be beneficial to assess latent trigger points in patients with stroke subjects without pain. It would also be beneficial to perform several interventional studies treating latent MTrPs after confirming the classification described in this study. r. These types of studies should be conducted to know if the presence of MTrPs of the muscles considered are correlated to clinical improvement of the patients despite the fact that they were not considered active MTrPs using the current clinical criteria. This may help analyze if the clinical criteria should be redefined for this specific population.

\section{Study limitations}

The main limitation of the study is represented the absence of a control group of subjects not affected by a neurological condition but with shoulder pain. However, we aimed to propose some preliminary considerations based upon our data and to pose the basis for further analyses in larger groups of patients affected by a stroke. We avoided the inclusion of non-neurologically impaired subjects because the existing literature provides a reliable and large database about pain parameters in healthy subjects of similar age. Another limitation may be that the third criterion that was used in this study to diagnose MTrPs (hypersensitive point) may be not reliable when patients have impaired sensation. Because of this, we conducted a secondary analysis excluding the HP criteria to diagnose

MTrPs and results were very similar (prevalence increased 4 points for the supraspinatus and infraspinatus, 2 points for the teres minor and no difference was found with the upper trapezius). Therefore we can assume that when patients have good communication skills, the use of this general criterion may not negatively affect the diagnostic reliability of MTrP in patients with stroke suffering from shoulder pain 


\section{Clinical Applications}

Prevalence of MTrPs was reasonably indicative of myofascial shoulder pain following a stroke although our cross sectional study couldn't define an association of cause and effect between shoulder pain and MTrPs. Although these findings suggest that palpation is useful to determine MTrPs in patients with hemiplegic shoulder pain, the criteria "referred pain familiar to the patient" should be reconsidered when determining if MTrPs are active. However clinicians should consider using MTrPs specific assessment and treatment for

the management of the hemiplegic shoulder pain.

1

\section{CONCLUSION}

This study shows that prevalence of MTrPs is high in patents following a stroke. Clinicians should consider using MTrPs specific assessment for the management of the hemiplegic shoulder pain. However, the criteria "referred pain familiar to the patient" should be reconsidered when determining if MTrPs are active in patients with stroke who may have a

\footnotetext{
sensory impairment. Further longitudinal studies are needed to determine the presence of MTrPs in this specific population.
}

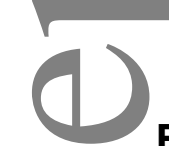

Funding sources and conflicts of interest: No founding sources or conflicts of interest were reported for this study.

\section{CONTRIBUTORSHIP INFORMATION}

Concept development: J.H.V, P.H, M.P.L, S.N.

Design: J.H.V, P.H, KV.

Supervision: J.H.V, S.N.

Data collection: M.P.L, P.P.

Analysis/interpretation: J.H.V, PH. 
Literature search: P.H, M.P.L, P.P.

Writing: J.H.V, K.V, P.H, M.P.L, R.C, S.N.

Critical review: J.H.V, K.V, P.H, M.P.L, R.C, S.N.

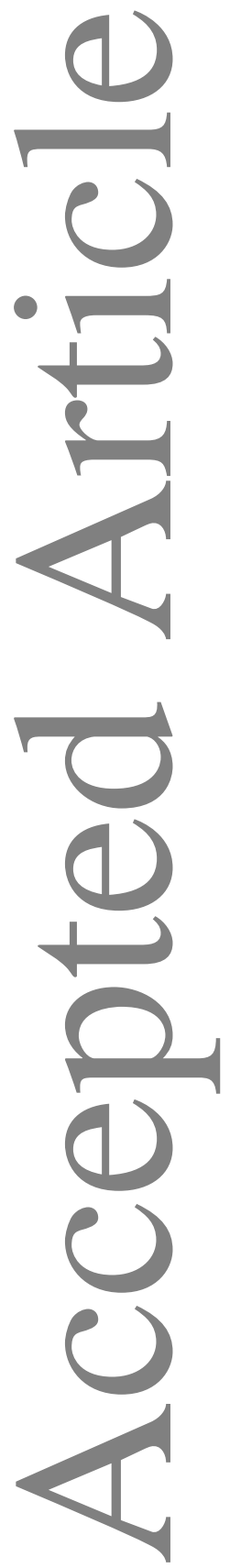


1. Lindgren, I., Jönsson, A.-C., Norrving, B. \& Lindgren, A. Shoulder pain after stroke: a prospective population-based study. Stroke 38, 343-348 (2007).

2. Koog, Y. H., Jin, S. S., Yoon, K. \& Min, B.-I. Interventions for hemiplegic shoulder pain: systematic review of randomised controlled trials. Disabil. Rehabil. 32, 282-291 (2010).

3. Borboni, A. et al. Robot-Assisted Rehabilitation of Hand Paralysis After Stroke Reduces Wrist Edema and Pain: A Prospective Clinical Trial. J. Manipulative Physiol. Ther. 40, 21-30 (2017).

4. Wofford, J. L., Mansfield, R. J. \& Watkins, R. S. Patient characteristics and clinical management of patients with shoulder pain in U.S. primary care settings: secondary data analysis of the National Ambulatory Medical Care Survey. BMC Musculoskelet. Disord. 6, 4 (2005).

5. Villafañe, J. H., Valdes, K., Anselmi, F., Pirali, C. \& Negrini, S. The diagnostic accuracy of five tests for diagnosing partial-thickness tears of the supraspinatus tendon: A cohort study. J. Hand Ther. Off. J. Am. Soc. Hand Ther. 28, 247-251; quiz 252 (2015).

6. Campbell, M. Problems With Large Joints: Shoulder Conditions. FP Essent. 446, 2530 (2016).

7. Pillastrini, P. et al. Effectiveness of neuromuscular taping on painful hemiplegic shoulder: a randomised clinical trial. Disabil. Rehabil. 38, 1603-1609 (2016).

8. Castaldo, M., Ge, H.-Y., Chiarotto, A., Villafane, J. H. \& Arendt-Nielsen, L. Myofascial trigger points in patients with whiplash-associated disorders and mechanical neck pain. Pain Med. Malden Mass 15, 842-849 (2014).

9. Villafañe, J. H. \& Herrero, P. Conservative treatment of Myofascial Trigger Points and joint mobilization for management in patients with thumb carpometacarpal osteoarthritis. J. Hand Ther. Off. J. Am. Soc. Hand Ther. 29, 89-92; quiz 92 (2016). 
10. Travell, J. G. \& Simons, D. G. Myofascial pain and dysfunction: the trigger point manual. (Lippincott, Williams \& Wilkins, 1998).

11. Bron, C., Dommerholt, J., Stegenga, B., Wensing, M. \& Oostendorp, R. A. High prevalence of shoulder girdle muscles with myofascial trigger points in patients with shoulder pain. BMC Musculoskelet. Disord. 12, 139 (2011).

12. Calvo-Lobo, C. et al. Dry Needling on the Infraspinatus Latent and Active Myofascial Trigger Points in Older Adults With Nonspecific Shoulder Pain: A Randomized Clinical Trial. J. Geriatr. Phys. Ther. $200141,1-13$ (2018).

13. Castaldo, M. et al. Association Between Clinical and Neurophysiological Outcomes in Patients With Mechanical Neck Pain and Whiplash-associated Disorders. Clin. J. Pain 34, 95-103 (2018).

14. Hanten, W. P., Olson, S. L., Butts, N. L. \& Nowicki, A. L. Effectiveness of a home program of ischemic pressure followed by sustained stretch for treatment of myofascial trigger points. Phys. Ther. 80, 997-1003 (2000).

15. Liu, L. et al. Effectiveness of dry needling for myofascial trigger points associated with neck and shoulder pain: a systematic review and meta-analysis. Arch. Phys. Med. Rehabil. 96, 944-955 (2015).

16. Tang, L., Li, Y., Huang, Q.-M. \& Yang, Y. Dry needling at myofascial trigger points mitigates chronic post-stroke shoulder spasticity. Neural Regen. Res. 13, 673-676 (2018).

17. Przysada, G. et al. Selected Factors Against Functional Performance in Patients in the Early Period After Stroke. Top. Geriatr. Rehabil. 33, 238 (2017).

18. von Elm, E. et al. [The Strengthening the Reporting of Observational Studies in Epidemiology (STROBE) statement: guidelines for reporting of observational studies]. Internist 49, 688-693 (2008). 
19. Zuil-Escobar, J. C., Martínez-Cepa, C. B., Martín-Urrialde, J. A. \& Gómez-Conesa, A. The Prevalence of Latent Trigger Points in Lower Limb Muscles in Asymptomatic Subjects. PM R 8, 1055-1064 (2016).

20. Bron, C., Franssen, J., Wensing, M. \& Oostendorp, R. A. B. Interrater reliability of palpation of myofascial trigger points in three shoulder muscles. J. Man. Manip. Ther. 15, 203-215 (2007).

21. Richard, L., Maitra, K., da Costa, B., Maillet, D. \& Ramsey, C. Patient Characteristics and Functional Outcomes in a 5-Year Retrospective Stroke Cohort. Top. Geriatr. Rehabil. 33, 98 (2017).

22. Villafañe, J. H. et al. Efficacy of Short-Term Robot-Assisted Rehabilitation in Patients With Hand Paralysis After Stroke: A Randomized Clinical Trial. Hand N. Y. N 13, 95102 (2018).

23. Jones, A.K, Brown, C.A. Post-stroke shoulder pain: nociceptive or neuropathic? Pain. 154,189. (2013)

24. Coskun Benlidayi,I., Basaran, S. Hemiplegic shoulder pain: a common clinical consequence of stroke. Pract Neurol. 14, 88-91. (2014)

25. Skootsky S. A., Jaeger B., Oye R. K. Prevalence of myofascial pain in general internal medicine practice. West J Med. 151,157-160. (1989)

26. Hidalgo-Lozano, A., Fernández-de-las-Peñas, C., Díaz-Rodríguez, L., GonzálezIglesias, J., Palacios-Ceña, D., Arroyo-Morales, M. Changes in pain and pressure pain sensitivity after manual treatment of active trigger points in patients with unilateral shoulder impingement: a case series. J Bodyw Mov Ther. 15, 399-404. doi: 10.1016/j.jbmt.2010.12.003. (2011) 
27. Fernández-De-Las-Peñas, C., Gröbli, C., Ortega-Santiago, R., Fischer, C.S., Boesch, D., Froidevaux, P., Stocker, L., Weissmann, R., González-Iglesias, J. Referred pain from myofascial trigger points in head, neck, shoulder, and arm muscles reproduces pain symptoms in blue-collar (manual) and white-collar (office) workers. Clin J Pain. 28,511-518 (2012)

28. Ribeiro, D.C., Belgrave, A., Naden, A., Fang, H., Matthews, P., Parshottam, S.. The prevalence of myofascial trigger points in neck and shoulder-related disorders: a systematic review of the literature. BMC Musculoskeletal Disord, 19, 252. (2018) 
Table 1. Myofascial trigger points diagnostic criteria

\begin{tabular}{|l|c|c|c|}
\hline \multicolumn{1}{|c|}{ Diagnostic Criteria } & \multicolumn{3}{|c|}{ Response } \\
\hline Taut band (TB) & Yes & No & Yes \\
\hline Palpable nodule (NE) & Yes & No & Yes \\
\hline $\begin{array}{l}\text { Hypersensitive point } \\
\text { (HP) }\end{array}$ & Yes & No & Yes \\
\hline $\begin{array}{l}\text { Referred pain familiar } \\
\text { to patient's pain (RP) }\end{array}$ & Yes & No & No \\
\hline Classification of MTrPs & Active & Not Present & Latent \\
\hline
\end{tabular}
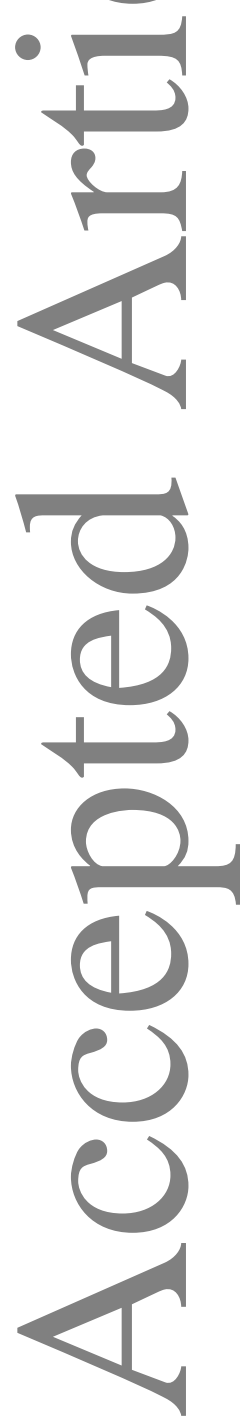
Table 3. Performance of the combination of 3 tests for latent and 4 tests for active MTrPs.

\begin{tabular}{lcc}
\hline & Sensitivity (\%) & + LR (95\% Cl) \\
\hline & Latent MTrPs, (Tb+NE+HN) \\
\hline Supraspinatus & 68 & $1.96(1.26-3.07)$ \\
Infraspinatus & 92 & $5.92(2.33-15.08)$ \\
Teres minor & 40 & $2.51(1.86-3.38$ \\
Upper trapezius & 62 & $2.55(1.70-3.83)$ \\
\hline \multicolumn{3}{c}{ Active MTrPs, (Tb+NE+HN+RP) } \\
\hline Supraspinatus & 34 & $2.35(1.76-3.13)$ \\
Infraspinatus & 50 & $2.33(1.64-3.32)$ \\
Teres minor & 12 & $2.14(1.72-2.65)$ \\
Upper trapezius & 20 & $1.31(0.85-2.04)$ \\
\hline
\end{tabular}

LR: Likelihood-ratio; MTrPs: Miofascial trigger points; TB: Tau band; NE: Nodule; NH: Hypersensitive nodule; and RP: Referred pain. 
Table 4. The Pearson's correlations between pain severity, disability and MTrPs variables.

\begin{tabular}{|c|c|c|c|c|c|c|c|c|c|}
\hline & \multicolumn{4}{|c|}{ Active } & \multicolumn{4}{|c|}{ Latent } \\
\hline & & \multicolumn{2}{|c|}{$\begin{array}{l}\text { Supra Infras } \\
\text { spinat pinat }\end{array}$} & \multirow{2}{*}{$\begin{array}{c}\text { Tere } \\
\mathbf{s} \\
\text { mino } \\
r\end{array}$} & \multirow{2}{*}{$\begin{array}{c}\text { Upper } \\
\text { trapez } \\
\text { ius }\end{array}$} & \multicolumn{2}{|c|}{$\begin{array}{l}\text { Supra Infras } \\
\text { spinat pinat }\end{array}$} & \multirow{2}{*}{$\begin{array}{l}\text { Teres } \\
\text { minor }\end{array}$} & \multirow{2}{*}{$\begin{array}{l}\text { Upper } \\
\text { trapeziu } \\
\text { s }\end{array}$} \\
\hline & & us & us & & & us & us & & \\
\hline \multirow{2}{*}{ VAS } & $\begin{array}{c}\text { Pearson } \\
\text { Correlation }\end{array}$ & $.31^{*}$ & .18 & .23 & .05 & $.35^{\star}$ & .17 & .21 & .09 \\
\hline & $p$-value & .03 & .21 & .12 & .74 & .01 & .24 & .15 & .52 \\
\hline \multirow{2}{*}{ DASH } & Pearson & $.32^{*}$ & .26 & .18 & .05 & .24 & $.31^{*}$ & .15 & .04 \\
\hline & p-value & .02 & .07 & .21 & .72 & .10 & .03 & .29 & .80 \\
\hline
\end{tabular}

- Indicates statistical significance $p<.05$

1

VAS: Visual Analog Scale; DASH: Disabilities of the Arm, Shoulder and Hand. 